chiffres moyens plus hauts ou à peine modifiés. La vache facile à effrayer $n^{0} 795$ a donné un lait contenant $1 \%$ en moins de matière grasse.

TABLEAU VII

Teneur en graisse dans les pourcentages du poids.

\begin{tabular}{|c|c|c|c|c|c|c|c|c|c|}
\hline $\begin{array}{l}\mathrm{N}^{0} \\
\text { de la } \\
\text { vache }\end{array}$ & Traites & $\begin{array}{c}\text { Graisse } \\
\text { moyenne } \\
\text { du lait } \\
\text { trait } \\
\text { à la main } \\
\text { après } \\
\text { traite } \\
\text { mécani- } \\
\text { que }\end{array}$ & $\begin{array}{l}\text { Graisse } \\
\text { du lait } \\
\text { trait } \\
\text { à ld } \\
\text { ma- } \\
\text { chine } \\
\text { le } \\
2 \text { jour }\end{array}$ & Différence & $\begin{array}{l}\mathrm{N}^{0} \\
\text { de la } \\
\text { vache }\end{array}$ & Traites & $\begin{array}{c}\text { Graisse } \\
\text { moyenne } \\
\text { du liat } \\
\text { trait } \\
\text { à là main } \\
\text { après } \\
\text { traite } \\
\text { mécani- } \\
\text { que }\end{array}$ & $\begin{array}{c}\text { Graisse } \\
\text { du lait } \\
\text { trait } \\
\text { à la } \\
\text { ma- } \\
\text { chine } \\
\text { le } \\
2^{2} \text { jour }\end{array}$ & Différence \\
\hline \multirow{4}{*}{109} & matin & 2,87 & 2,3 & $-0,57$ & \multirow{4}{*}{788} & matin & 3,82 & 3,85 & $+0,03$ \\
\hline & midi & 4,10 & 3,9 & $-0,2$ & & midi & 4,15 & 4,80 & $+0,65$ \\
\hline & soir & 4,45 & 4,5 & $+0,05$ & & soir & 4,33 & 3,85 & $-0,48$ \\
\hline & total & 3,81 & 3,57 & $-0,24$ & & total & 4,10 & 4,17 & $+0,07$ \\
\hline \multirow{4}{*}{775} & matin & 4,00 & 6,5 & $+2,5$ & \multirow{4}{*}{795} & matin & 3,31 & 2,2 & $-1,11$ \\
\hline & midi & 4,45 & 6,2 & $+1,75$ & & midi & 4,40 & 3,15 & $-1,25$ \\
\hline & soir & 4,49 & 3,45 & $-1,04$ & & soir & 4,44 & 3,35 & $-1,09$ \\
\hline & total & 4,31 & 5,38 & $+1,07$ & & total & 4,05 & 2,90 & $-1,15$ \\
\hline \multirow{4}{*}{793} & matin & 2,66 & 5,00 & $+3,66$ & \multirow{4}{*}{830} & matin & 3,07 & 3,3 & $+0,23$ \\
\hline & midi & 3,45 & 5,00 & $+1,55$ & & midi & 3,47 & 3,75 & $+\quad 0,28$ \\
\hline & soir & 3,39 & 4,2 & $+0,81$ & & soir & 3,90 & 3,50 & $-0,40$ \\
\hline & total & 3,17 & 4,73 & $+1,56$ & & total & 3,48 & 3,52 & $+0,04$ \\
\hline
\end{tabular}

Nous pouvons conslure que lors du changement des conditions de la traite, l'adaptation de l'organisme de la vache se fait plus vite pour la teneur en graisse que pour le rendement du lait.

Si nous considérons les résultats acquis pendant cet essai préalable auquel ont été soumises des vaches non accoutumées à la traite mécanique, nous arrivons à la conslusion :

La trayeuse mésanique "Alfa " n'a pas d'influence nuisible sur les vaches tranquilles et saines. Le rendement pendant l'essai ne s'est pas abaissé, et la teneur en graisse n'a pas souffert.

(A suivre).

\title{
LES CULTURES EN STRIES POUR REIMPLACER LES CULTURES SUR PLAQUES
}

Par le professeur $D^{r}$ R. BURRI, directeur de l'Etablissement de Bactériologie laitière du Liebefeld (Berne).

Le procédé des cultures sur plaques de КосH, modifié par l'utilisation des boîtes de Petri, est depuis de nombreuses années d'un emploi général pour les recherches bactériologiques, tant qualitatives que quantitatives. Il résout de la manière la plus heureuse le problème de la séparation des germes et de leur développement ultérieur qui permet, 
au besoin, un examen plus approfondi des colonies. Le fait que l'introduction de ce procédé a donné lieu à de nombreuses découvertes intéressantes dans le domaine de la bactériologie médicale, en montre toute l'importance.

Il présente cependant les inconvénients suivants :

10 Par solidification du mélange (milieu nutritif et matériel bactérien) les germes se fixent à des hauteurs différentes dans la conche, ainsi qu'à la surface, de sorte qu'une même espèce bactérienne peut donner des colonies d'apparences différentes.

$2^{\circ}$ Facilité de contamination des cultures par les bactéries de l'air.

$3^{\circ}$ Dessiccation rapide du milieu et, par là, mort prématurée des cultures,

$4^{\circ}$ Frais élevés de matériel (verrerie, chauffage), longueur des manipulations.

Le premier inconvénient est connu depuis longtemps, on l'évite en ne mélangeant plus le matériel bactérien et le milieu nutritif, mais en l'étalant à la surface du milieu de culture soliditié. On appelle ces cultures : cultures en surface. Le matériel bactérien peut être étalé soit au moyen d'un vaporisateur, soit au moyen d'un pinceau ou encore par striage. Ce mode d'ensemencement du milieu nutritif, comparé à celui d'ensemencement parfusion, présente de sérieux avantages; il est connu en bactériologie médicale ou technique sous le nom de cultures en stries. Il va de soi qu'il ne permet pas de déterminations quantitatives.

Partant de ce fait expérimental, à savoir qu'une anse de platine calibrée, dans des conditions toujours identiques, prend toujours une même quantité d'un liquide déterminé, nous a vons éla boré et décrit (1) un procédé permettant la détermination du taux bactérien du lait, que nous désignons sous le nom de cultures quantitatives en stries. Ce procédé est caractérisé par l'emploi d'une anse calibrée (contenant $1 \mathrm{mgr}$. de lait), dont le contenu est étalé en stries, à la surface d'un milieu solidifié et incliné, contenu dans une éprouvette de $160 / 18 \mathrm{~m} / \mathrm{m}$, le milieu étant à base de gélose. Avant l'emploi, il faut s'assurer qu'il n'y a pas d'eau de condensation dans le tube. On étale le milligramme de lait (prélevéavec l'anse qu'on a fait affleurer la surface du lait et non plonger dans le lait) par un mouvement sinueux rapide, sur la partie la plus grande possible de l'agar incliné ; on obtient ainsi de la façon la plus simple et dans un laps de temps très court, de très belles cultures, de sorte qu'on peut procéder à la numération des germes et déterminer ensuite leur nature. Comme on le voit, ce procédé réunit les avantages des cultures en surface et ceux des cultures en tube. Pour les taux bactériens les plus usuels (100-100.000 germes par $\left.\mathrm{cm}^{3}\right)$, on aura le taux bactérien en multipliant par 1.000 le nombre des colonies qui se sont

(1) The quantitative smear-culture : a simple means for the bactériological examination of milk. World's Dairy Congress 1928. Report p. 690. 
développées. Lorsque le taux bactérien est plus élevé, il ne peut être apprécié avec certitude, on préparera alors des dilutions du lait avec de l'eau. Par suite de la modification de la tension superficielle du lait ainsi dilué, la capacité de l'anse est moindre; si le lait a été dilué au $1 / 100^{\mathrm{e}}$, le nombre des colonies doit être multiplié par 1,4 .

A

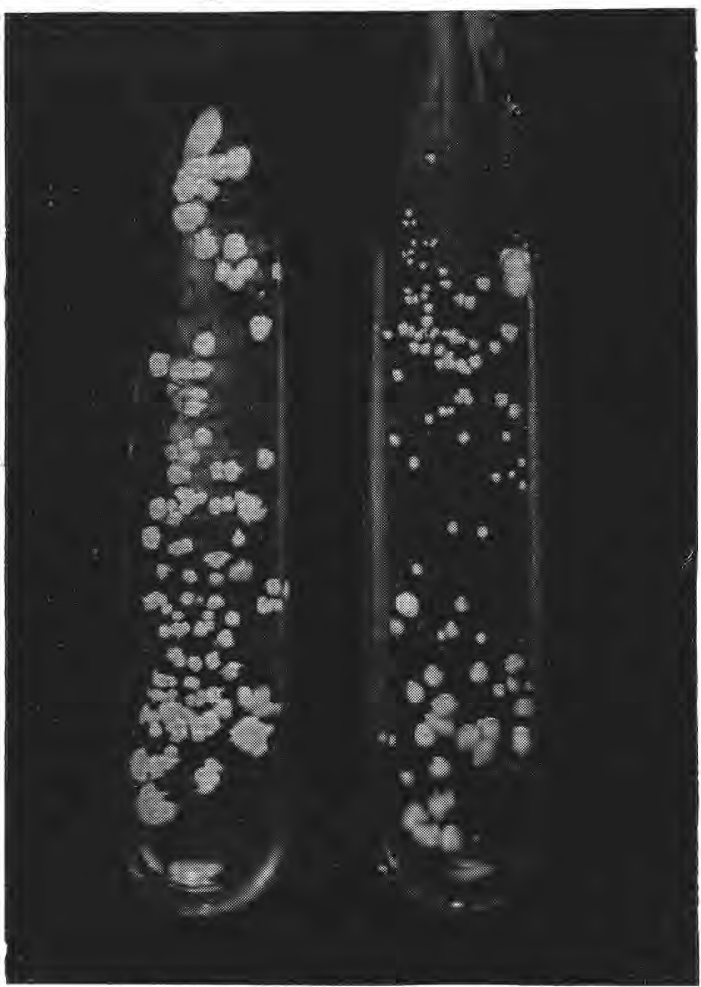

A: Culture en stries de lait condensé

B : " " „ de consommation

En général, on détermine le taux bactérien du lait sans dilution, la comparaison des résultats de l'ensemencement en stries avec ceux de l'ense mencement sur plaque par fusion est tout enfaveur de la 1re méthode.

En considérant plus spécialement le contrôle du lait, on reconnaîtra à ce nouveau procédé les avantages suivants :

1. - Simplicité extraordinaire qui permet, même à un profane, de déterminer le taux bactérien avec une exactitude suffisante.

2. - Le nombre des germes obtenus est en général plutôt plus élevé qu'avec les cultures ordinaires sur plaque ; cela peut s'expliquer par le fait que la surface de l'agar incliné offre à la grande majorité des bactéries des conditions de développement optimum plus favorables que la couche du milieu nutritif des cultures sur plaque. C'est ainsi que les 
bactéries facultativement anaérobies, même à caractère anaérobie prononcé comme les lactobacilles, se développent.

3. - Economie a pprécia ble de temps et de matériel, par le fait que le dispositif pour la fusion du milieu et les boîtes de Pétri sontsupprimés ; la préparation, abstraction faite des cas où l'on est obligé de procéder à une dilution du matériel à ensemencer, est faite en moins d'une minute.

4. - Elimination des infections par les germes de l'air et par la certitude plus grande des résultats de la numération, spécialement lorsque le nombre des colonies développées est peu considérable.

5. - Dangerfortement diminué de dessiccation, et par là, possibilité de conservation plus longue, comme pour les cultures en stries; aptitude à un examen qualitatif ultérieur et possibilité de conservation comme pièce à conviction en cas de contestation.

6. - Comme les colonies sont uniquement des colonies de surface, les espèces ou groupes bactériens apparaissent d'une façon caractéristique, ce qui permet à une personne un peu exercée d'avoir non seulement des résultats quantitatifs, mais aussi une image qualitative des conditions bactériennes.

7. - Ce procédé, grâce à son extraordinaire simplicité, peut trouver son emploi dans n'importe quelle section d'un-système d'approvisionnement en lait ou d'une exploitation laitière, les cultures ensemencées pouvant être transportées au laboratoire très facilement, sans précautions spéciales.

Il va de soi que l'emploi de ces cultures quantitatives en stries n'est pas limité au lait, mais qu'il peut, pour ainsi dire, être appliqué dans tous les cas où l'on utilisait autrefois le procédé de culture sur plaque. Cependant, une limite lui semble imposée, dans le cas où le matériel à examiner est pauvre en germes et où l'emploi d'un milligramme donnerait des résultats négatifs. Pour le lait trait aseptiquement, nous avons procédé ainsi avec avantage : en ensemençant 5 öses sur un tube d'agar, de sorte que le nombre de colonies doit être multiplié par 200 pour ramener le taux bactérien à $1 \mathrm{gr}$.

En augmentant le nombre des tubes pour un objet déterminé à examiner, le facteur d'accroissement peut être abaissé à volonté. De cette manière, on obtiendra un résultat plus satisfaisant qu'avec les cultures sur plaques où, naturellement, Jes contaminations par l'air jouent un rôle d'autant plus sérieux que le nombre des germes de l'objet à examiner est plus faible.

Signalons encore que les cultures en stries sur agar incliné rendent des services précieux dans les cas où l'on ne s'inquiète pas de déterminer le nombre des germes : par exemple, lorsqu'il s'agit d'avoir une idée sur la nature d'un mélange de germes ou de déterminer la pureté des cultures. Dans ce cas, l'étalement du matériel bactérien, liquide ou solide, se fait au moyen d'un fil de platine ordinaire ; on utilisera alors 3 tubes pour a voir, dans l'un au moins, la répartition exacte des germes. 